\title{
Copper tubing failure due to ant-nest corrosion
}

\author{
Athanasios Vazdirvanidis ${ }^{l}$, Sofia Papadopoulou ${ }^{l}$, Spyros Papaefthymiou ${ }^{2}$, \\ George Pantazopoulos ${ }^{l, *}$ and Dionysios Skarmoutsos ${ }^{3}$ \\ ${ }^{1}$ ELKEME-Hellenic Research Centre for Metals S.A., 32011 Oinofyta-Viotia, Greece \\ ${ }^{2}$ National Technical University of Athens, School of Mining and Metallurgical Engineering, Division \\ of Metallurgy and Materials, Laboratory of Physical Metallurgy, 9, Her. Polytechniou str., Zografos, \\ GR-157 80, Athens, Greece \\ ${ }^{3}$ ELVALHALCOR S.A. - HALCOR Copper Tube division, 32011 Oinofyta -Viotia, Greece
}

\begin{abstract}
Ant-nest corrosion is a type of premature and localized failure, which is observed in $\mathrm{Cu}$ tubes used mainly in air-conditioning and heat exchanger units, induced by the presence of organic matter. Leakage takes place within a short period of time after unit installation and frequently causes pipeline and equipment damage accompanied with loss of refrigerant liquid. In the present paper, case histories concerning such type of insidious corrosion phenomena are presented. Metallographic examination on cross-sections revealed that a particular pitting corrosion mechanism is activated, driving to a tunnelling-type "tortuous" pit propagation, causing rapid metal tube perforation and leakage.
\end{abstract}

\section{Introduction}

Copper is the first member of Group IB of the Periodic Table having atomic number 29 and electronic configuration $[\mathrm{Ar}] 3 \mathrm{~d}^{10} 4 \mathrm{~s}^{1}$. The loss of the outermost s-electron produces the cuprous ion $\mathrm{Cu}^{+}$and a second electron may be lost from the filled d-shell to form the cupric ion $\mathrm{Cu}^{2+}$. The availability of the d-electrons for coordination allows copper to readily form complexes with such species as $\mathrm{NH}_{3}$ and $\mathrm{CN}$ [1]. As copper is not an inherently reactive element, it is not surprising that the rate of corrosion is usually low. Due to its high thermal conductivity is frequently used in unit installations such as air conditioners and refrigerators. Copper tubes from different applications exhibit various types of corrosion: pitting corrosion [2-3], erosion-corrosion [4], microbiological influenced corrosion [5] etc.

Temperature, chlorine, natural organic matter and microbial extracellular polymeric substances are among the factors most commonly cited as influencing copper corrosion in soft waters [6]. But $\mathrm{Cu}$ can get corroded even from free chlorine chlorinated domestic water [7]. Often, after a few months of usage, copper tubes of heat exchanger units exhibit corrosion leakages, a fact that led many researchers to study the cause of such phenomena. Environmental effect of coolant leakages due to $\mathrm{Cu}$ failure and the production of copper scrap can be critical to change flora and fauna's stability and therefore it is quite important to prevent those defects [8]. The deposits that are formed by many types of corrosion can be dissolved or removed by using treatments with solutions of inorganic or organic acids for a proper time and temperature range [9].

USEPA emphasises that water pipe corrosion and ageing is one of most serious concerns related to water distribution pipelines and may pose public health problems. Electrochemical corrosion is the main reason for exterior corrosion of cast and ductile pipes, which results in pipe deterioration in the form of corrosion pit on pipe walls [4]. The corrosion pit

\footnotetext{
*Corresponding author: gpantaz@elkeme.vionet.com
} 
will grow with time and eventually leads to a pipe leakage. The physical deterministic models estimate the corrosion pit of a pipe and their impact on residual strength of a pipe [10]. The physical mechanisms that lead to pipe leakage are often complex and not completely understood. The pipes having internal protection by lining and/or coating are less susceptible to corrosion. Modern metallic pipes are mostly manufactured with internal linings to prevent internal corrosion from soft or aggressive water. However, older metallic pipes may be unlined and would therefore be susceptible to internal corrosion due to stress and deposits concentration [11].

Only few works exist concerning the study of this type of corrosion in heat exchanger units. Typical examples of such case studies are referred in Refs. [12-14]. The synergistic effect of ant-nest corrosion and stress corrosion was addressed in Ref. [15]. There is a rather significant value of such industrial research aiming to analyse, understand and prevent failures, which eventually exhibit high environmental impact and material/equipment losses. Ant-nest corrosion constitutes a representative example of a progressive deterioration process, possessing high advancement rate and low detectability. The name of this corrosion failure is originated from the morphology of the problematic area, which consists of corroded pinhole traces of several microns size. The main contributing factor to this phenomenon is the presence of carboxylic acids, which participate to the corrosion reactions together with moisture and dissolved oxygen. The scope of the present work is to identify critical issues of ant-nest corrosion in order to suggest ways to prevent such failures. For this reason the results of selected case histories will be summarized in the frame of this article.

\section{Experimental procedure}

The present study is a compilation of a variety of characteristic case histories investigated within almost a three-years' time period and were related to thin walled $\mathrm{Cu}-\mathrm{DHP}$ tubes for air-conditioning (ACR) as well as to thicker tubes for sanitary applications, which exhibited leakage after a very short operation duration. Visual inspection of the surfaces of samples was performed after longitudinal cross-section, while metallographic specimens were made by transverse cross-sections for observation of the corrosion type. Stereoscopic observation of the tubes was performed with a Nikon SMZ 1500 stereo-microscope, while metallographic examination of mounted specimens (transverse and longitudinal sections) was accomplished by a Nikon Epiphot 300 inverted metallographic microscope. Higher magnification observation was carried out using a FEI XL40 SFEG Scanning Electron Microscope (SEM) under $20 \mathrm{kV}$ accelerating voltage, coupled with an EDAX Energy Dispersive X-ray Spectroscopy (EDS) Apollo XF Silicon Drift Detector (SDD) of $60 \mathrm{~mm}^{2}$ area.

\section{Results}

The outer surfaces of these tubes were often without serious indications of corrosion or severe mechanical damage, while the inner surfaces were heavily corroded exhibiting complex and branching channels, covered by corrosion products, while microcracks were found on each one of them. The corroded tubes and relevant features of the corrosion products were presented in Figs. 1-4. In optical micrographs [Fig. 1 (b) and (c)] a branched propagation with oxide deposits inside the caverns was exhibited initiating from tube's inner surface and copper oxides with polarized light. A similar type of corrosion propagation, initiated from the outer surface in this case, is shown in Fig. 2. The morphology of corrosion deposits and pit formation is shown in Fig. 4. 

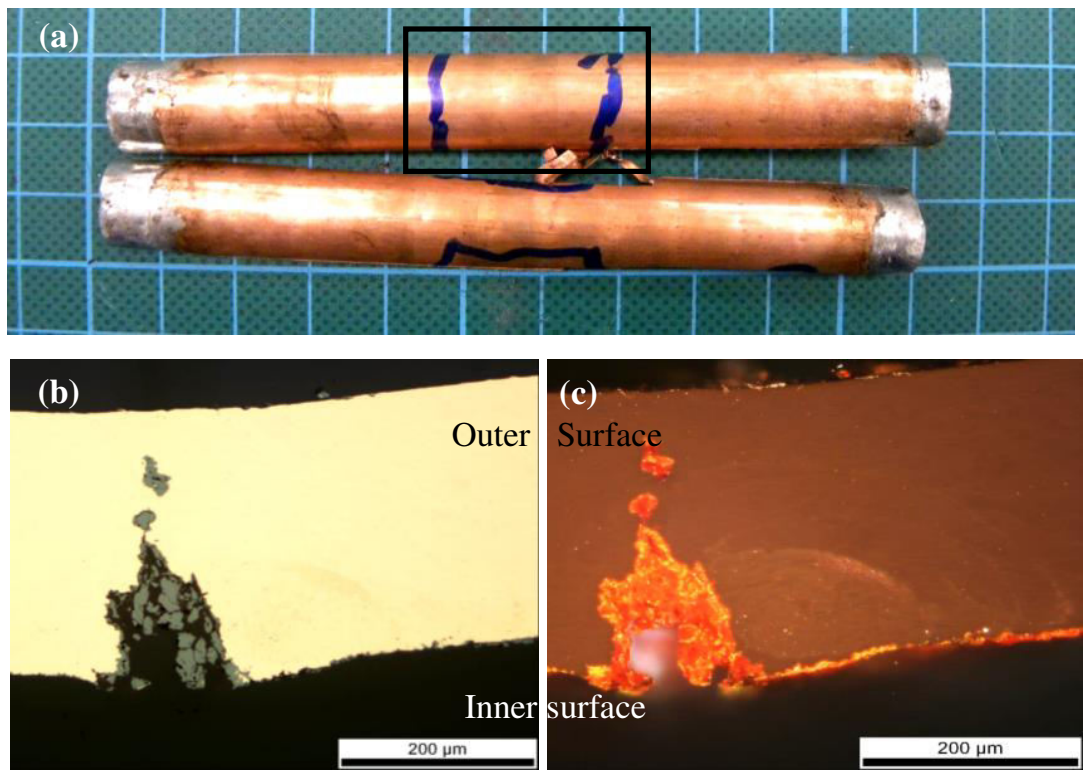

Fig. 1. (a) Macrograph of sample examined (Ø12.7x0.35 for ACR) indicating area of interest, (b) transverse cross-section showing the copper corrosion products (inside-out corrosion) and (c) same area observed under polarized light - copper oxides are reddish.
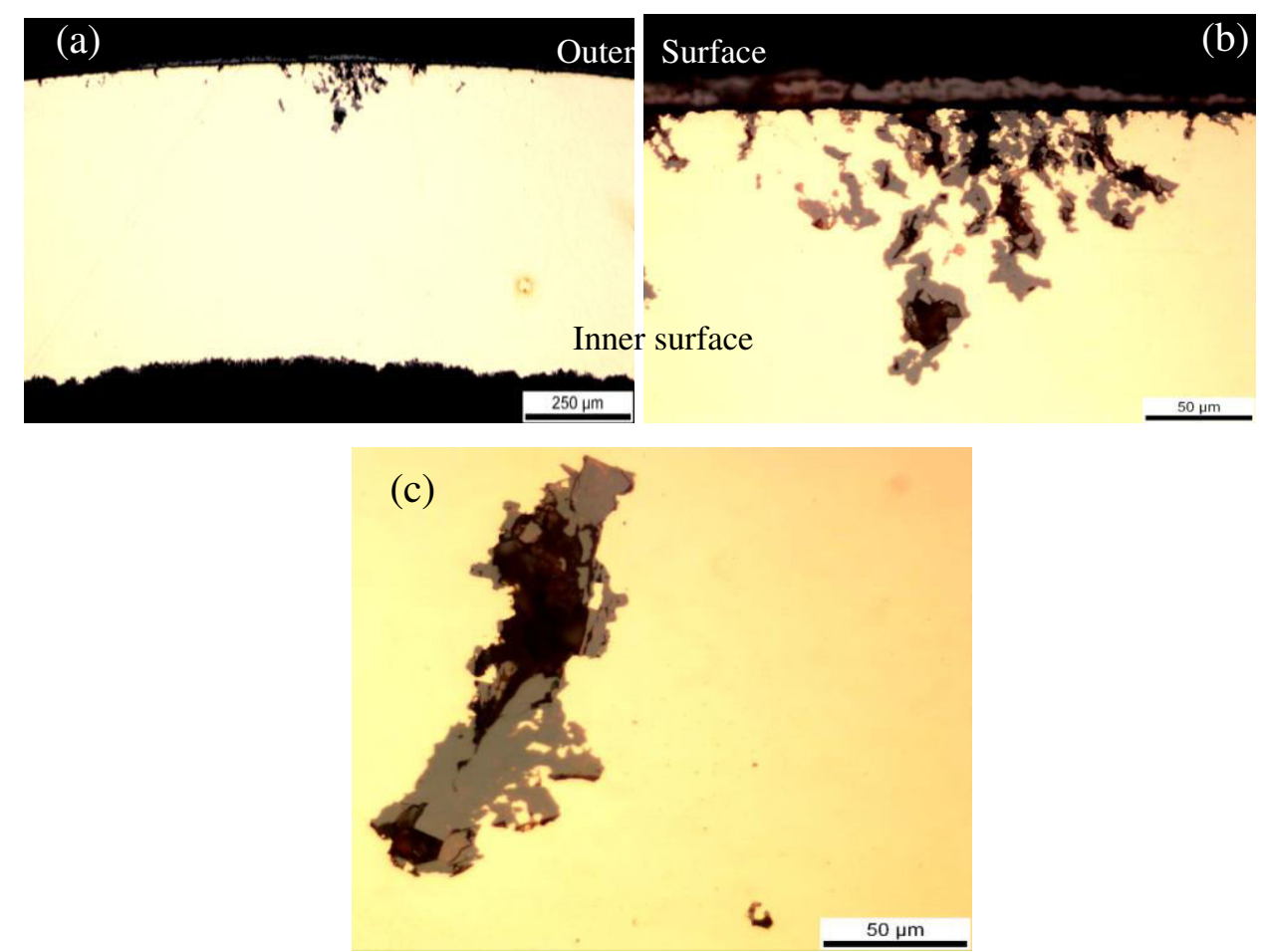

Fig. 2. Optical micrographs, cross-section of another tube showing ant-nest corrosion type failure (Ø $15 \times 0.70$ for sanitary use). Note the accumulation of the corrosion products close to the outer surface. 
Electron micrographs showing pits' formation and coarse oxides containing also $\mathrm{O}, \mathrm{S}, \mathrm{Al}$, $\mathrm{K}$ and $\mathrm{C}$ are illustrated in Fig. 4.
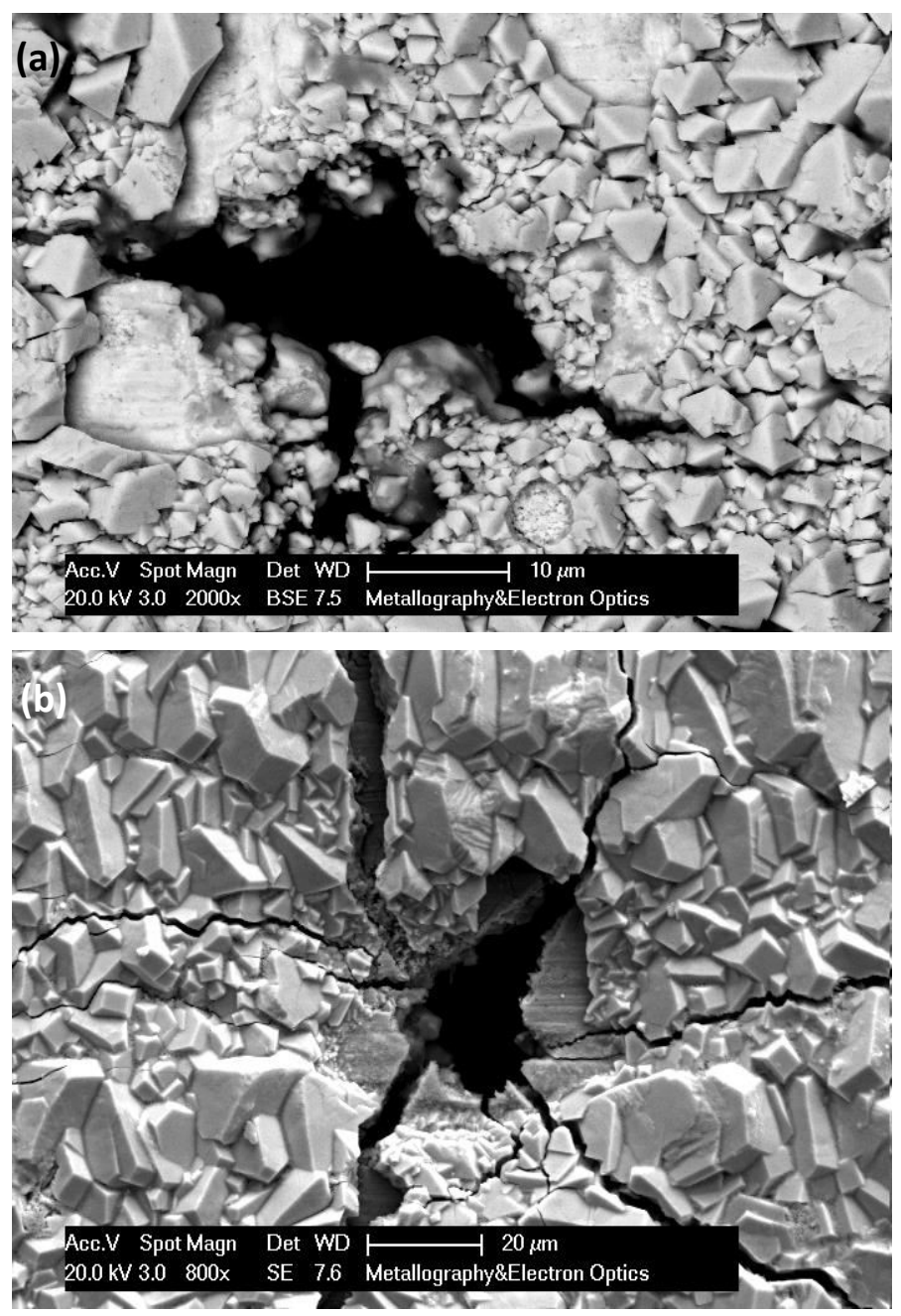

Fig. 3. (a) SEM micrographs of the inner surface showing pits' formation. Note the cubic crystalline oxide products. 


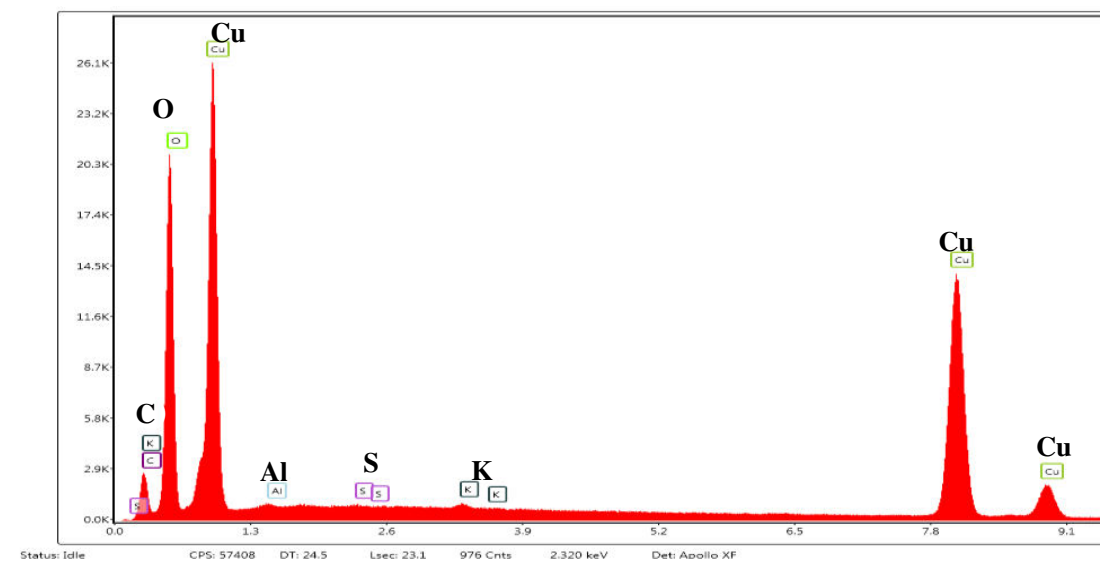

Fig. 4. Typical Energy dispersive X-ray spectrum; full frame analysis of the corrosion products.

Corrosion was propagated through branched and tortuous corrosion channels filled with coarse corrosion products. Chemical analyses exhibited mostly $\mathrm{O}, \mathrm{S}, \mathrm{Al}, \mathrm{K}$ but also $\mathrm{C}$ which could be attributed to organic matter presence. All the above findings are consistent to the action of ant-nest corrosion mechanism.

\section{Discussion}

The form of the corrosion propagation path together with the morphology and chemical composition of the corrosion products and short lifetime constitute signs of ant-nest corrosion process. Similar findings are also presented in relevant literature for refrigerating units and $\mathrm{Cu}$ round tube/Al plate finned type heat exchangers [12,14]. Ant-nest corrosion is a rapid corrosion process which is usually propagating through grain boundaries and results in a perforation of a hole in a thin-wall tube, usually in a very short time period (within weeks or months). Ant-nest corrosion most commonly appears in the copper tubing of air conditioning or refrigeration equipment and is mostly found in $\mathrm{Cu}-\mathrm{DHP}$, which is the main material of construction. Organic compounds used during the fabrication and joining of the copper tubes (e.g. the residues of synthetic lubricating oils, drawing oils, finning lubricants, and/or degreasing and detergent cleaners), if not completely removed, may be decomposed to carboxylic acid in presence of air and moisture. The exposure of copper surfaces to carboxylic acids, such as formic acid $(\mathrm{HCOOH})$, acetic acid $\left(\mathrm{CH}_{3} \mathrm{COOH}\right)$, propionic acid $\left(\mathrm{C}_{2} \mathrm{H}_{5} \mathrm{COOH}\right)$ and butyric acid $\left(\mathrm{C}_{3} \mathrm{H}_{7} \mathrm{COOH}\right)$ stimulates the reaction leading to the formation of copper carboxylates. The corrosion mechanism is also described in detail in Ref. [12]. Ant-nest corrosion attack initiates at some local surface discontinuity, i.e. such as a surface defect or a scratch in the oxide film. These sites are attacked by the carboxylic acid, which penetrates through the oxide film. In moist conditions, the copper base metal oxidizes and dissolves, according to reaction (1) leading to the formation of small corrosion pits characteristic of ant-nest corrosion:

$$
\mathrm{Cu}(s) \rightarrow \mathrm{Cu}^{+}(\mathrm{aq})+e
$$

Under the presence of carboxylate anions, the dissolved copper ions react forming unstable $\mathrm{Cu}$ (I) carboxylate, which oxidizes further to form $\mathrm{Cu}$ (II) carboxylate and copper oxide $\mathrm{Cu}_{2} \mathrm{O}$ according to the chemical reactions [Eqs. (2) and (3)]: 


$$
\begin{gathered}
\mathrm{Cu}^{+}(a q)+\mathrm{HCOO}^{-} \rightarrow \mathrm{Cu}(\mathrm{HCOO})(a q) \\
4 \mathrm{Cu}(\mathrm{HCOO})(a q)+1 / 2 \mathrm{O}_{2} \rightarrow 2 \mathrm{Cu}(\mathrm{COOH})_{2}(s)+\mathrm{Cu}_{2} \mathrm{O}(s)
\end{gathered}
$$

The solid constituents $\mathrm{Cu}(\mathrm{COOH})_{2}$ and $\mathrm{Cu}_{2} \mathrm{O}$ precipitate in the interior of the corrosion pit. Due to the volume expansion associated with the formation of $\mathrm{Cu}_{2} \mathrm{O}$, microcracks may initiate and radiate outward within the corrosion pit wall under the imposed wedging effect. The microcracks liberate an appreciable fraction of pure copper surface area and the process advances within the cracks between $\mathrm{Cu}$ (II) carboxylate and pure unaffected $\mathrm{Cu}$. Consequently, the $\mathrm{Cu}$ (I) complex organic compound is re-produced according to the following chemical reaction [see Eq. (4)]:

$$
\mathrm{Cu}(\mathrm{COOH})_{2}(s)+\mathrm{Cu}(s) \rightarrow 2 \mathrm{Cu}(\mathrm{HCOO})(\mathrm{aq})
$$

Therefore, the reactions (4) and (5) autocatalytically taken place, forming tunnels, until final through wall-perforation occurs. The standard oxygen cathodic reactions (5) \& (6) are the following:

$$
\begin{array}{r}
\mathrm{O}_{2}+2 \mathrm{H}_{2} \mathrm{O}+4 e \rightarrow 4 \mathrm{OH} \\
\mathrm{O}_{2}+4 \mathrm{H}+4 e \rightarrow 2 \mathrm{H}_{2} \mathrm{O}
\end{array}
$$

The end-points of the pits or the advancing channels act as anodes for $\mathrm{Cu}$ oxidation, and the walls of the channels and the surface of the copper tube act as cathodes for oxygen (cathodic) reduction reactions. The presence of carboxylic acid in the humid atmosphere catalyzes this reaction mechanism. There are three factors that are necessary for ant-nest corrosion to occur, and they should be in effect simultaneously. These are: (i) moisture, (ii) air, and (iii) an organic compound (carboxylic acid). If any of the three components is consumed or removed, ant-nest corrosion is terminated [12]. The inner and often outer tube wall surfaces is usually covered by copper (hydro)oxide products, while the presence of $\mathrm{C}$, $\mathrm{Al}, \mathrm{S}, \mathrm{K}$ is observed as a result of contaminants, deposited on the surface or infiltrated in to the crack area, see also Refs. [12,15].

It is assumed that damages have resulted in local through-thickness discontinuities, which contributed to the leakage observed by the user. Summarizing the above findings, based on pit morphology and propagation, as well corrosion product shape and composition, it could be inferred that leakages were the outcome of a rapid corrosion process. The collected experimental evidence together with the short lifetime of the tube is rather suggestive of the occurrence of ant-nest corrosion mechanism. Similar findings are also presented in relevant literature for refrigerating units and $\mathrm{Cu}$ round tube/Al plate finned type heat exchangers [12-14].

\section{Conclusions}

The examined tubes exhibited leakages after short periods of usage (a few months). Since the defected/damaged areas were not visible to the naked eye, tube degradation proceeds to final failure and leakage without any prior warning or "alerting signal". The investigation findings advocate the occurrence of ant-nest corrosion as the pertinent failure mechanism, which was rapidly evolved, having caused severe damage to the heat exchanger (and refrigeration) units with serious consequences to environmental and material losses. The main findings of the current investigation can be summarized as follows: 
1. Corrosion had propagated from the inner towards the outer tube surface and vice versa following a tortuous and branching path, causing tube wall perforation.

2. The inner tube wall surfaces were covered by coarse copper (hydro)oxide products, while the presence of $\mathrm{C}, \mathrm{Al}, \mathrm{S}, \mathrm{K}$ has been also identified.

3. It is assumed that damages have resulted from local through-thickness discontinuities, which contributed to the leakage observed. The presence of $\mathrm{C}$ indicated possible presence of organic matter (e.g. lubricant).

Further research and acquisition of additional knowledge, focused on the allocation of the nature of organic residues (e.g. lubricants, cleaning agents), which play an important role on the activation of ant-nest corrosion mechanism is recommended, in order to obtain a valuable insight of the degradation process mechanism. Possible prevention of such phenomena might involve the development and realization of the suitable cleaning/degreasing procedures of heat exchanger tubes in order to remove effectively lubricant and organic substance residues, which constitute significant factors of the imminent corrosion mechanisms. Drastic removal of organic contaminant even if achieved cannot exclude the possibility of contamination during operation related to the operating environment. Ant-nest corrosion is mainly focusing on the operating conditions of the indoor heat exchanger units. The application of an experimental simulation method of antnest corrosion will further facilitate the verification of the effectiveness of the proposed corrective actions and test potential alternatives regarding copper chemical composition to combat such insidious corrosion phenomena.

\section{References}

1 ASM International Handbook. Pitting. Copper and Copper Alloys, (2001).

2 J.R. Myers, A Cohen, Materials Performance, 34 (10), 60-62, (1995).

3 D.A. Lytle, M.N. Nadagouda, Corrosion Science, 52, 1927-1938, (2010).

4 B. Kuznicka, Engineering Failure Analysis. 16, 2382-2387, (2009).

5 A.M. Olszewski, J. Failure Analysis and Prevention, 7(4), 238-246, (2007).

6 N. Boulay, M. Edwards, Water Res. 35,683-690 (2001).

7 M. G. Fontana, Corrosion Engineering. McGraw-Hill International Editions, 91-105 (1987).

8 A. Fateh, M. Aliofkhazraei, A.R. Rezvanian, Arabian Journal of Chemistry, In press, (2017).

9 Zajicek, D. Atlas J. Coombs and O. T. Water Res. 16, 8-62 (1982).

10 Kjellstrom, Karin Lundgren and Tord. Sustainability,5, 3116-3128 (2013).

11 Yan, Jimin. Risk Loughborough University, 28-76, (2006).

12 H. Peltola, M. Lindgren, Engineering Failure Analysis, 51, 83-97, (2015). 
13 K. Chandra, V. Kain, P.S. Shetty, R. Kishan, Engineering Failure Analysis, 37,1-11, (2014).

14 S. Nasrazadani, S. Nakka, J. Failure Analysis and Prevention, 16, 189-196, (2016).

15 J. Zhou, L. Yana, J. Tanga, Z. Suna, L. Ma. Engineering Failure Analysis, 83, 9-16, (2018). 